\title{
Phonological Awareness Test
}

National Cancer Institute

\section{Source}

National Cancer Institute. Phonological Awareness Test. NCI Thesaurus. Code C160862.

A test to assess the ability of the respondent to repeat multi-syllable nonsense words. It

is is used to assess an individual's ability to code and temporarily store information

phonologically. This ability is related to verbal memory and language acquisition. 